Neurosurg Focus 8 (4):Article 2, 2000, Click here to return to Table of Contents

\title{
Gene therapy of brain tumors: problems presented by physiological barriers
}

\author{
James P. Basilion, Ph.D., Tomotsuga IChiKaWa, M.D., \\ and E. Antonio Chiocca, M.D., Ph.D. \\ Department of Radiology and Center for Molecular Imaging Research, and Neurosurgical Service \\ and Molecular Neuro-Oncology Laboratory, Massachusetts General Hospital, Harvard Medical \\ School, Boston, Massachusetts
}

\begin{abstract}
The explosion of molecular techniques for gene discovery and their application to a variety of diseases has uncovered numerous gene abnormalities that can result in disease. These discoveries have provided the needed understanding and genetic materials to apply gene therapy approaches in the treatment of several diseases, including those of the central nervous system. A variety of different anticancer complementary DNAs (cDNA) have been shown to possess biological efficacy when used in the appropriate experimental setting. However, efficient and effective delivery of these cDNAs remains a major obstacle for future clinical applications. The focus of this review will be to describe the obstacles that impede the process of gene therapy and oncolytic viral therapy of brain tumors and to describe how important new discoveries derived from other disciplines are being used to address problems encountered in the gene/ viral therapy of this disease.
\end{abstract}

\author{
KEY WORDS • gene therapy • brain neoplasm • blood-brain barrier • \\ magnetic resonance imaging • nuclear imaging
}

\section{CURRENT THERAPY IN BRAIN TUMORS}

Malignant gliomas remain one of the most difficult tumors to treat. These tumors affect approximately 15,000 individuals per year in the United States. They present as focal masses within the brain substance with infiltrating margins in the normal brain. After the patient is diagnosed, the patient's few remaining months are generally punctuated by a steady decline in quality of life with cumulative neurological and medical morbidities. The current status of therapeutic treatments for malignant brain tumors, such as glioblastoma multiforme, is at best palliative. It includes, when possible, surgical excision of the neoplastic mass, often guided by intraoperative navigational techniques and electrocorticographic mapping of involved motor and language areas in awake patients. This is followed by the delivery of radiation to the area from which the tumor has been excised and surrounding brain in an attempt to destroy infiltrating tumor cells not yet visible intraoperatively or by conventional imaging. Ad-

\footnotetext{
Abbreviations used in this paper: ${ }^{111}$ In oxine $={ }^{111}$ Indium 8-hydroxyquinoline; $\mathrm{BBB}=$ blood-brain barrier; $\mathrm{BBTB}=$ blood-brain tumor barrier; cDNA = complementary DNA; CNS = central nervous system; HSV-tk = herpes simplex virus thymidine kinase; MION = monocrystalline iron oxide nanoparticle; $\mathrm{MR}=$ magnetic resonance.
}

juvant chemotherapy consists of systemic administration of nitrosourea agents. When undertaken in patients with this disease, these measures have increased the average lifespan by a few months. Additional treatments such as local intratumoral implantation of polymers to release chemotherapeutic agents, high-dose radiation to the tumor bed by stereotactic radiosurgery, and novel chemotherapeutic regimens (such as CPT11, temozolamide, and polyvinyl chloride) promise to increase further the clinician's ability to provide palliation to the patient. On the horizon, angiogenesis modulation, novel gene-based therapeutics, immunotherapy, and oncolytic viral therapy appear to be poised for testing of their safety and efficacy in clinical trials. It is likely that these modalities will provide further extension of higher-quality life for patients, and it is imperative that additional investigation of their potential be performed.

\section{VIRAL-BASED GENE THERAPY}

Tumors of the CNS are a devastating illness, and, despite the progress made in recent history, there has been little improvement in survival statistics in recent decades even with implementation of aggressive multimodal treatment. The lack of progress has prompted the search for different, more efficacious treatments for the disease. Of these, gene therapy approaches have generated significant 
interest. All clinical trials in which gene therapy is applied, to date, have used gene therapy as an adjuvant to surgery, radio-, and chemotherapy. A variety of different approaches has been used to alter expression of pathogenic gene products or to cause expression of therapeutic genes in targeted tissues. These approaches require modalities that can effectively deliver the gene or gene product to the diseased tissue. Replacement of defective genes was one of the first applications of gene therapy and has been applied in several diseases, such as cystic fibrosis (transmembrane conductance regulator), ${ }^{39}$ adenosine deaminase deficiency (ADA), ${ }^{3}$ or Gaucher disease ( $\beta$-glucocerebrosidase deficiency). ${ }^{66}$ Therapeutic genes have been inserted into cells to produce proteins that are toxic or are capable of converting innocuous prodrug into toxic drugs. Some of the first examples of the former are tumor necrosis factor, which has been introduced into tumor-infiltrating lymphocytes to boost anticancer activity ${ }^{75}$ and $p 53$, which when expressed in p53-deficient cells, results in apoptosis. ${ }^{11,82}$ An example of the latter is the viral enzyme HSV-tk; which, unlike mammalian tk, phosphorylates ganciclovir that then becomes toxic to cells. ${ }^{84}$ Several of these strategies as well as other novel approaches have been attempted in the treatment of malignant glioma: 1) delivery of prodrug-activating genes that confer sensitivity to toxic metabolites, ${ }^{1,12,15,60,70,83}$ 2) replacement of tumor suppressor genes known to be deficient in gliomas usually resulting in tumor apoptosis, $, 528,29,373$ ) delivery of genes resulting in supression of angiogenesis, ${ }^{19,58,85} 4$ ) delivery of genes resulting in activation of host antitumor immune responses, ${ }^{26,46,48} 5$ ) antisense cDNA delivery to regulate negatively tumor-related protein, ${ }^{26,47}$ and 6) conditionally replicating viruses that selectively infect and destroy tumor cells. ${ }^{10,12,13,17,34-36,59}$ Conditional replicating viruses can destroy tumor cells. This is a form of gene therapy because transfer of viral lytic genes provide the observed anticancer effect. Furthermore, the use of oncolytic viruses to deliver prodrug-activating enzymes has resulted in highly effective therapy. ${ }^{15}$ Although these approaches significantly vary in strategy, they all share a common goal: to deliver the therapeutic gene or virus efficiently and specifically to the targeted tissue. This is perhaps one of the most daunting problems for gene therapy, and only recently have we begun to become familiar with the underlying physiology and biochemistry affecting viral delivery to the CNS and other sites. In the future greater understanding of these biological parameters should allow for better gene transfer and more effective therapies.

\section{OBSTACLES TO GENE THERAPY IN BRAIN TUMORS}

Many of the impediments to gene therapy result from poor gene delivery and stable expression in targeted tissues. Strategies that will result in successful gene delivery will require matching the delivery methodology to the targeted tissue. A single gene delivery system cannot ideally be applied in all human genetic or malignant disease. For example, delivery of a therapeutic gene to brain tumors might require the delivery vehicle to traverse the BBTB and accumulate with a high local concentration in the tumor, whereas an alternative delivery system may be re- quired to target metastatic disease or cancers of the blood. Targeting sites other than the brain would not require traversing the BBB and might result in more efficient delivery of the gene therapy vectors. ${ }^{2,93}$ Additionally, the expression requirements for the transferred gene will dictate the choice of vectors. In the treatment of cancers with gene therapy, it may be disadvantageous for the therapeutic gene to be stably integrated into the host genome, whereas this may be a requirement for gene-replacement therapy. A partial list of the vectors developed for gene therapy is summarized in Table 1. Each of these vectors systems has both its advantages and disadvantages, and all have been used successfully for in vitro and/or in vivo gene transfer. (reviewed in ${ }^{9,16,44,49,52,56,64,68,69,89,92}$ ) It should be emphasized that viral vectors have shown the most efficiency in delivery to cells. However, their main disadvantage remains that they elicit an immune response that can limit the anatomical extent and temporal perseverance of transgene expression.

Brain tumors commonly are refractory to chemo- or radiotherapy and result in the rapid demise of the patient. Additionally complicating the treatment is the finding that several of these tumors manifest as multiple discrete masses within the brain. The most malignant form of primary brain tumors (glioblastoma multiforme) can manifest as multicentrically distinct masses within the brain, a universally fatal occurrence. ${ }^{6,78,90}$ In clinical trials in which adenoviral vectors or HSV-based vectors are used as adjuvants to conventional interventions, the investigators have attempted to deliver therapeutic ( $H S V$ - $t k)$ or suicide ( $p 53)$ genes primarily by direct inoculation into the tumor mass through freehand, stereotactic, or catheter-based methods (Trask TW, et al: unpublished data; Alavi JB, et al: unpublished data). ${ }^{8,72,76}$ These routes of administration, although likely to cause local focal necrosis in injected tumors, are very unlikely to result in direct viral effects on other tumors within the brain. Results obtained from trials of this type have shown poor viral infection, with most infection localized in direct proximity of the needle tacks or the periphery of implanted virus-producing cells. Presumably this is caused by the limited diffusion of large viral particles within the tumor. To address these limitations we and others have used two strategies: 1) conditionally replicat-

TABLE 1

Partial list of gene transfer vector systems viral vectors

adenovirus adenoassociated virus Epstein-Barr virus HSV

papova virus vaccinia virus retrovirus lenti virus hybrid viral vectors nonviral vectors DNA-polylysine complexes liposomes lipofectin ligand-targeted liposomes hybrid viral \& nonviral vectors 
ing virus have been developed to replicate and propagate selectively within tumor cells to increase the anatomical area of tumor infection; and 2) delivery of oncolytic or gene therapy viruses injected into the circulation, with the potential delivery of virus and viral effects against all the tumor loci within the brain commonly supplied by neovascular growth. ${ }^{10,16,40}$

As described previously, most brain tumor gene therapy strategies require viral delivery to targeted tissue within the CNS. Regardless of the gene transfer vector or the use of lytic viruses, all of these approaches are associated with several barriers to infection including the BBB, BTB, innate immunity, and other factors that neutralize the viruses before they reach the targeted tissue. Innate immunity is the apparent ability of a naive animal or human to inhibit infectivity of a virus without prior sensitization. In animals or humans who have been exposed to the virus previously, there is a full immune response and significant inhibition of the injected virus. For the purposes of this review, we will concentrate on the effect of innate immunity and the BBB/BBTB on viral delivery as well as on recent advances in modulating these barriers.

\section{Blood-Brain Barrier}

In the early 1900s Ehrlich ${ }^{25}$ conducted the first experiments describing the concept of a BBB. In reports since that time the authors have described the physiological basis of this "concept," and it has been shown that the BBB is primarily caused by unique intercellular contacts between and among capillary endothelial cells. These "tight junctions" have been extensively studied, and the findings have allowed for some manipulation of the BBB's permeability. ${ }^{50,51}$ The most important factors in determining drug delivery into the CNS are lipid solubility, molecular mass, and charge. The normal BBB restricts trans- and pericellular movement of blood-born molecules, effectively filtering most ionized, water-soluble molecules greater than 180 daltons in mass..$^{50,61}$ The result of this efficient filtering mechanism has been to render treatment of CNS metastases relatively ineffective, even in cases of systemic cancers that respond well to chemotherapeutic agents (for example, small cell lung cancer, lymphoma, and breast cancer). In the case of brain tumors, the $\mathrm{BBB}$ is frequently not intact in the center of the malignancy as demonstrated by computerized tomography and MR imaging. ${ }^{50}$ However, the presence of an intact BBB at the proliferating edge of the tumor has been suggested to be one of the major contributing factors to the failure of chemotherapy in the treatment of CNS neoplasms. ${ }^{14,50,74}$ To achieve therapeutic levels of chemotherapeutic drugs within the brain, different properties of the BBB have been exploited to disrupt the BBB, including hyperosmotic disruption and receptor-induced $\mathrm{BBB}$ permeability modification.

Osmotic BBB disruption has been reported to occur in a number of animal systems ${ }^{62}$ and is currently being used clinically to increase delivery of chemotherapeutic agents for the treatment of brain tumors in humans. It is believed that osmotic shock disruption of the $\mathrm{BBB}$ results in the shrinkage of endothelial cells, opening the tight junctions and allowing passage of larger molecules including antibodies and viral particles. Because it is approved for ad- ministration in patients, the most investigated hypertonic solution is derived from mannitol. Permeability of the $\mathrm{BBB}$ is increased significantly (5-15 minutes) after the infusion of mannitol, and it normalizes within 2 hours. $^{73}$ In the rat the delivery of viral particles can be increased fourfold by using this approach. ${ }^{63}$ These also have demonstrated transduction of tumor tissue by viruses administered after osmotic BBB disruption. ${ }^{20,22}$

Attempts to modulate the permeability of the BBB pharmacologically have also been undertaken. Mediators of inflammatory response, such as leukotrienes, can induce transient vascular leakage, allowing reversible increased permeability of blood vessels that temporally open the BBB. Of particular interest in the clinical and the laboratory setting is a vasodilatory molecule called bradykinin and its more stable, specific analog RMP-7. ${ }^{21}$ These molecules are thought to act by simulating the B2receptors on endothelial cells. In model systems in which investigators have tested the efficacy of the titration of either bradykinin or RMP-7, increased permeability has been demonstrated in selected tumor models (RG-2 glioma in rats) without altering the permeability of vessels in surrounding brain. This change in permeability was translated to a 2.8-fold increase for intravenously administered low-molecular weight molecules and greater than a 10fold increase for high-molecular weight dextran. ${ }^{42,57} \mathrm{How}-$ ever, there is significant variability among models presumably due to variability in B2-receptor expression and other unknown biochemical characteristics among tumor capillaries. Variations in permeability resulting from osmotic BBB disruption have also been shown. The pharmacological disruption, similar to osmotic disruption, is transient, returning to basal level in approximately 20 minutes. ${ }^{42}$ Pharmacological disruption of the $\mathrm{BBB}$, with increase in permeability to chemotherapeutic agents, results in a greater efficacy of these agents. In the RG-2 glioma tumor model rats treated with RMP-7 and carboplatin survived significantly longer than those treated with carboplatin alone. ${ }^{57}$ Additionally RMP-7 has been shown to increase brain tumor permeability to ganciclovir, an observation that may be important for the tk/ganciclovir gene therapy strategy. ${ }^{53}$ Bradykinin has also been used to demonstrate an increase in MIONs and HSV particles in the 9L glioma model. ${ }^{71}$ In recent studies in our laboratories we have also demonstrated an effect of bradykinin on the delivery of other viral particles (unpublished data). Currently we are testing to determine if osmotic and pharmacological disruption of the BBB can be combined to enhance further the delivery of viral particles through the $\mathrm{BBB}$. Despite the success, much work is still needed to overcome the formidable BBB and BBTB for delivery of gene therapy and viral vectors to brain tumors.

\section{Innate Barriers}

A common problem in achieving therapeutic levels of many molecules injected into the circulation is the "firstpass" effect of the liver in which active molecules are significantly removed from the circulation. This is also true with virus, and as much as $35 \%$ of injected HSV can be found in the liver soon after intravenous injection. ${ }^{77} \mathrm{Al}-$ though this is potentially an excellent effect when targeting tumors of the liver, it is detrimental to delivering virus 
to brain tumors via systemic administration. Regional delivery through the arterial blood supply may provide better delivery of the virus to the brain by eliminating firstpass effects caused by the liver. In an effort to augment further the delivery of virus to the brain, the addition of $\mathrm{BBB}$ disrupting agents such as mannitol or disrupters of the BBTB, such as bradykinin or its analog RMP-7, have been shown to increase infection of brain tumors after intraarterial administration of $\mathrm{HSV}$ or adenovirus. ${ }^{7,65,71}$ Despite these efforts, viral infectivity of brain tumors after intraarterial administration remains relatively poor. These results have led us to consider other potential innate barriers to viral infectivity. It seems likely that blood components that inactivate the effects of administered virus might pose a significant inactivation barrier. Serum lipoproteins, ${ }^{38,80,81}$ fatty acids,,${ }^{4,87}$ immunoglobulin, ${ }^{18,43}$ and complement ${ }^{24,54,79}$ have all been reported to bind HSV and inactivate its ability to infect cells. To escape the surveillance of such innate antiviral mechanisms, HSV expresses proteins that: inactivate $\mathrm{C} 3$, a major component of the complement pathway; inhibit the function of $\mathrm{IgG}$; and prevent myosin heavy chain isoform class presentation in infected cells. ${ }^{23,33,54,55}$

We have investigated the effects of innate immunity on viral infectivity in vitro. Using an in vitro viral neutralization assay, we recently demonstrated that preimmune plasma harvested from athymic and immunocompetent rodents, as well as from humans, can inactivate the in vitro transducing ability of HSV. ${ }^{40}$ The innate activity is present at high levels in the preimmune plasma and appears to be dependent on calcium. Other blood components seem, at least in part, to be involved in this innate inhibitory activity. The innate activity is partially suppressed by in vivo pretreatment of rodents with agents that deplete complement, such as cobra venom factor. ${ }^{40}$ In vitro mild heat treatment of the plasma also significantly inhibits the innate antivirus activity of preimmune plasma, which is consistent with the belief that complement has some role in the antivirus activity. However, we have also potentially ruled-in other blood components. In vivo pretreatment of rodents with cyclophosphamide, a generalized inhibitor of B cell-produced immunoglobulin, also partially suppresses the innate antiviral activity measured in vitro. This result was also confirmed in vivo. A single systemic dose of cyclophosphamide administered in rodents significantly increased the number of animals with virus-infected brain tumors and the extent of propagation of viral infection within individual brain tumors. ${ }^{40}$ More recently we demonstrated that cobra venom factor reverses the innate antiviral activity of rodent preimmune serum in vitro against $\mathrm{HSV}^{41}$ and that in vivo cobra venom factor pretreatment increases the number of positively infected tumor cells within a neoplastic intracerebral mass after intraarterial administration of HSV. A combination of CPA and cobra venom factor results in greater tumor infection by HSV than the use of either factor alone. ${ }^{41}$ These results support a model in which intravascular virus infection and propagation occur within tumors, which is initially modulated by innate host antiviral response, which itself can be manipulated pharmacologically to increase virus infectivity.

The ability to deliver active virus to multiple tumors within an organ such as the brain provides the first step toward rendering effective gene- or viral-based therapies in the treatment of an illness currently refractory to more conventional therapies. Further elucidation of the mechanisms by which the virus moves from vascular spaces into tumor, as well as the effects on innate antivirus activity against both the virus and virally infected cells, will improve this therapeutic strategy. Although eliminating one component of the immune system may render the virus more toxic toward normal cells, potential avenues to minimize this exist. For instance, viral infection can be targeted more selectively to tumor cells in three ways: 1) by altering the viral ligands that promote cellular entry; 2) by using viruses engineered with tissue-specific promoters to drive therapeutic or suicide gene expression; or 3) by selecting transgenes whose toxicity to nontargeted tissues is limited. If the limited and transient manipulation of these innate and early humoral responses-without affecting more prolonged cellular responses-provides an effective anticancer effect, it is possible that the toxicity related to prolonged viral therapy, which has recently gained much attention in the media, may be avoided.

\section{IN VIVO IMAGING OF VIRUS DISTRIBUTION AND GENE EXPRESSION}

Our current knowledge of the biodistribution and/or in vivo pharmacokinetics of vector gene delivery systems is incomplete and relies mainly on the staining of biopsy or postmortem tissue samples and polymerase chain reaction analysis of virally delivered DNA sequences. A better understanding of the effects of BBB manipulation on virus delivery to the brain and brain tumors is essential for a gene therapy approach to combat brain tumors. Schellingerhout and colleagues ${ }^{77}$ have devised a real-time, noninvasive method by which to monitor virus delivery in vivo. The basis of their approach was to radio-label enveloped viruses, such as HSV and retrovirus, using ${ }^{111}$ In oxine, a lipophilic complex known to traverse cell membranes of eukaryotic cells (for example, leukocytes ${ }^{86}$ or liposomes ${ }^{45,67}$ ). In the intracellular compartment dissociation of ${ }^{111}$ In oxine into ${ }^{111}$ In-ion and free oxine occurs. Liberated ${ }^{111} \mathrm{In}$-ions bind to intracellular and nuclear proteins. ${ }^{86}$ It has been postulated by Schellingerhout, et al., ${ }^{77}$ and Thakur and colleagues ${ }^{86}$ that a similar partitioning takes place in enveloped viruses (HSV), resulting in the ${ }^{111} \mathrm{In}-$ ion being stably associated with the virus tegument or capsid proteins. Following intravenous administration of ${ }^{111}$ In-labeled virus, nuclear imaging of viral distribution suggested the presence of virus in the brain. These imaging data were confirmed in biodistribution studies revealing $7 \%$ of radioactivity had been excreted and, the remaining organ distribution was as follows (in percent injected dose/organ): liver, $37.4 \pm 7.9 \%$, spleen; $14.1 \pm 3.5 \%$; kidney, $8.3 \pm 2.9 \%$; lung, $2.3 \pm 0.4 \%$; pancreas, $0.9 \pm$ $0.2 \%$; blood, $0.9 \pm 0.2 \%$; brain; $0.09 \pm 0.0 \%$; and carcass, $28.8 \pm 2.8 \%$. These preliminary studies demonstrated the potential that such a labeling method could be used for both nuclear imaging of viron distribution and for biodistribution studies. ${ }^{77}$ In other studies some investigators are attempting to use ${ }^{99 \mathrm{~m}} \mathrm{Tc}$ labeling of adenovirus particles. ${ }^{94}$ In collaboration with Weissleder and coworkers, we currently are using the indium-oxine labeling techique 
to determine the postintraarterial injection quantitative effect of osmotic and pharmacological BBB-disrupting agents on virus distribution. Novel technologies and studies of this kind will help define the parameters most important for disruption of the BBB in the rat, which will hopefully be translated into meaningful improvements in virus delivery and tumor therapy in the clinic.

Several investigators have also been able to monitor transgene expression in vivo. Several groups have attempted to measure transgene expression by using as a model the therapeutic $H S V$ - $t k$ gene and radiolabeled marker substrates..$^{30-32,88}$ These studies were able to demonstrate that there was a tight correlation between the level of gene expression and enzyme-dependent accumulation of the marker substrate. These tools allowed for noninvasive assessment and distribution of $H S V$ - $t k$ expression and, therefore, an estimate of gene-transfer efficiency. Similar studies are being performed to assess the effects of other therapeutic genes. ${ }^{30}$ However, these technologies suffer from lower spatial resolution. To take advantage of the high spatial resolution and anatomical detail achievable by using MR imaging we have applied this technique to measure transgene expression. In preliminary studies we were able to demonstrate that overexpression of an engineered transferrin receptor cDNA led to an increase in uptake of an engineered transferrin receptor-targeted MION. Uptake of the targeted MION was readily detectable by using MR imaging and the findings correlated well with receptor expression levels, as measured by RNA blots. ${ }^{91}$ We are now incorporating this MR imaging marker gene into amplicon-based gene delivery systems to monitor transfer and expression of therapeutic genes to targeted tissues.

\section{SUMMARY}

The results of the preclinical studies we have reviewed clearly demonstrate the need for more investigation into the factors that impinge on virus infection and transduction of targeted tissues. Whereas the studies reviewed here and elsewhere ${ }^{16,27,50}$ clearly demonstrated the cancer-related efficacy of gene or viral therapy when therapeutic doses of virus are achieved at target tissues, it is also clear that there exist several barriers to achieving therapeutic doses in vivo. Significant advances in current viral delivery technology are needed to achieve effective gene or viral therapy of brain cancer. The two barriers reviewed here, the $\mathrm{BBB}$ and innate antiviral activities, appear to have multiple interacting components and will require additional study so that we may gain an understanding sufficient to manipulate these components and increase viral infectivity without increasing viral toxicity. However, the development of novel imaging methodologies to detect the effect of agents on viral distribution and transgene expression, in vivo and in real time, will certainly speed our progress toward understanding and manipulating these parameters.

\section{References}

1. Aghi M, Kramm CM, Chou TC, et al: Synergistic anticancer effects of ganciclovir/thymidine kinase and 5-fluorocytosine/ cytosine deaminase gene therapies. J Natl Cancer Inst 90: 370-380, 1998
2. Anderson SC, Johnson DE, Harris MP, et al: p53 gene therapy in a rat model of hepatocellular carcinoma:intraarterial delivery of a recombinant adenovirus. Clin Cancer Res 4:1649-1659, 1998

3. Anonymous: The ADA human gene therapy clinical protocol. Hum Gene Ther 1:327-329, 1990

4. Ash RJ: Butyrate-induced reversal of herpes simplex virus restriction in neuroblastoma cells. Virology 155:584-592, 1986

5. Badie B, Drazan KE, Kramar MH, et al: Adenovirus-mediated p53 gene delivery inhibits 9L glioma growth in rats. Neurol Res 17:209-216, 1995

6. Barnard RO, Geddes JF: The incidence of multifocal cerebral gliomas. A histologic study of large hemisphere sections. Cancer 60:1519-1531, 1987

7. Barnett FH, Rainov NG, Ikeda K, et al: Selective delivery of herpes virus vectors to experimental brain tumors using RMP7. Cancer Gene Ther 6:14-20, 1999

8. Berger MS, Prados M, Van Gilder JC, et al: Gene therapy for the treatment of recurrent glioblastoma multiforme with in vivo transduction using the herpes simplex-thymidine kinase gene/ ganciclovir system. J Neurosurg 86:378A, 1997 (Abstract)

9. Bilbao G, Gomez-Navarro J, Curiel DT: Targeted adenoviral vectors for cancer gene therapy. Adv Exp Med Biol 451: 365-374, 1998

10. Bischoff JR, Kirn DH, Williams A, et al: An adenovirus mutant that replicates selectively in p53-deficient human tumor cells. Science 274:373-376, 1996

11. Bouvet M, Bold RJ, Lee J, et al: Adenovirus-mediated wildtype p53 tumor suppressor gene therapy induces apoptosis and suppresses growth of human pancreatic cancer. Ann Surg Oncol 5:681-688, 1998

12. Boviatsis EJ, Park JS, Sena-Esteves M, et al: Long-term survival of rats harboring brain neoplasms treated with ganciclovir and a herpes simplex virus vector that retains an intact thymidine kinase gene. Cancer Res 54:5745-5751, 1994

13. Boviatsis EJ, Scharf JM, Chase M, et al: Antitumor activity and reporter gene transfer into rat brain neoplasms inoculated with herpes simplex virus vectors defective in thymidine kinase or ribonucleotide reductase. Gene Ther 1:323-331, 1994

14. Brightman MW, Hori M, Rapoport SI, et al: Osmotic opening of tight junctions in cerebral endothelium. J Comp Neurol 152:317-325, 1973

15. Chase M, Chung RY, Chiocca EA: An oncolytic viral mutant that delivers the CYP2B1 transgene and augments cyclophosphamide chemotherapy. Nat Biotechnol 16:444-448, 1998

16. Chung RY, Chiocca EA: Gene therapy for tumors of the central nervous system. Surg Oncol Clin North Am 7:589-602, 1998

17. Coffey MC, Strong JE, Forsyth PA: Reovirus therapy of tumors with activated Ras pathway. Science 282:1332-1334, 1998

18. Costa J, Rabson AS, Yee C, et al: Immunoglobulin binding to herpes virus-induced $\mathrm{Fc}$ receptors inhibits virus growth. Nature 269:251-252, 1977

19. Dameron KM, Volpert OV, Tainsky MA, et al: Control of angiogenesis in fibroblasts by p53 regulation of thrombospondin1. Science 265:1582-1584, 1994

20. Davidson BL, Allen ED, Kozarsky KF, et al: A model system for in vivo gene transfer into the central nervous system using an adenoviral vector. Nat Genet 3:219-223, 1993

21. Doctrow SR, Abelleira SM, Curry LA, et al: The bradykinin analog RMP-7 increases intracellular free calcium levels in rat brain microvascular endothelial cells. J Pharmacol Exp Ther 271:229-237, 1994

22. Doran SE, Ren XD, Betz AL, et al: Gene expression from recombinant viral vectors in the central nervous system after bloodbrain barrier disruption. Neurosurgery 36:965-970, 1995

23. Dubin G, Basu S, Mallory DL, et al: Characterization of domains of herpes simplex virus type 1 glycoprotein $\mathrm{E}$ involved in Fc binding activity for immunoglobulin $\mathrm{G}$ aggregates. $\mathbf{J}$ Virol 68:2478-2485, 1994 
24. Dubin G, Fishman NO, Eisenberg RJ, et al: The role of herpes simplex virus glycoproteins in immune evasion. Curr Top Microbiol Immunol 179:111-120, 1992

25. Ehrlich P: Uber die Beziehungen von chemische Constitution, Vertheilung, und Pharmakologischer Wirkung. Collected Studies in Immunology. New York: John Wiley, 1906, pp 567-595

26. Fakhrai H, Dorigo O, Shawler DL, et al: Eradication of established intracranial rat gliomas by transforming growth factor beta antisense gene therapy. Proc Natl Acad Sci USA 93: 2909-2914, 1996

27. Fathallah-Shaykh H: New molecular strategies to cure brain tumors. Arch Neurol 56:449-453, 1999

28. Fueyo J, Gomez-Manzano C, Puduvalli VK, et al: Adenovirusmediated p16 transfer to glioma cells induces G1 arrest and protects from paclitaxel and topotecan: implications for therapy. Int J Oncol 12:665-669, 1998

29. Fueyo J, Gomez-Manzano C, Yung WK, et al: Suppression of human glioma growth by adenovirus-mediated $\mathrm{Rb}$ gene transfer. Neurology 50:1307-1315, 1998

30. Gambhir SS, Barrio JR, Herschman HR, et al: Assays for noninvasive imaging of reporter gene expression. Nucl Med Biol 26:481-490, 1999

31. Gambhir SS, Barrio JR, Phelps ME, et al: Imaging adenoviraldirected reporter gene expression in living animals with positron emission tomography. Proc Natl Acad Sci USA 96: 2333-2338, 1999

32. Gambhir SS, Barrio JR, Wu L, et al: Imaging of adenoviraldirected herpes simplex virus type 1 thymidine kinase reporter gene expression in mice with radiolabeled ganciclovir. J Nucl Med 39:2003-2011, 1998

33. Goldsmith K, Chen W, Johnson DC, et al: Infected cell protein (ICP) 47 enhances herpes simplex virus neurovirulence by blocking the CD8+ T cell response. J Exp Med 187:341-348, 1998

34. Goldstein DJ, Weller SK: Factor(s) present in herpes simplex virus type 1-infected cells can compensate for the loss of the large subunit of the viral ribonucleotide reductase: characterization of an ICP6 deletion mutant. Virology 166:41-51, 1988

35. Goldstein DJ, Weller SK: Herpes simplex virus type 1-induced ribonucleotide reductase activity is dispensable for virus growth and DNA synthesis: isolation and characterization of an ICP6 lacZ insertion mutant. J Virol 62:196-205, 1988

36. Goldstein DJ, Weller SK: An ICP6::lacZ insertional mutagen is used to demonstrate that the UL52 gene of herpes simplex virus type 1 is required for virus growth and DNA synthesis. J Virol 62:2970-2977, 1988

37. Hsiao M, Tse V, Carmel J, et al: Intracavitary liposome-mediated $\mathrm{p} 53$ gene transfer into glioblastoma with endogenous wildtype $\mathrm{p} 53$ in vivo results in tumor suppression and long-term survival. Biochem Biophys Res Commun 233:359-364, 1997

38. Huemer HP, Menzel HJ, Potratz D, et al: Herpes simplex virus binds to human serum lipoprotein. Intervirology 29:68-76, 1988

39. Hyde S, Gill DR, Higgins CF, et al: Correction of the ion transport defect in cystic fibrosis transgenic mice by gene therapy. Nature 362:250-255, 1993

40. Ikeda, K, Ichikawa T, Wakimoto H, et al: Oncolytic virus therapy of multiple tumors in the brain requires suppression of innate and elicited antiviral responses. Nat Med 5:881-887, 1999

41. Ikeda KH, Wakimoto T, Ichikawa S, et al: Complement depletion facilitates the infection of multiple brain tumors by intravascular, replication-conditional herpes simplex virus mutant. J Virol (In press)

42. Inamura T, Nomura T, Bartus RT, et al: Intracarotid infusion of RMP-7, a bradykinin analog: a method for selective drug delivery to brain tumors. J Neurosurg 81:752-758, 1994

43. Johansson PJ, Kjellen L: Inhibition of herpes simplex virus growth caused by preparations of animal immunoglobulins is not dependent on Fc-Fc receptor interactions. Intervirology 29:334-338, 1988

44. Kaplitt MG, Makimura H: Defective viral vectors as agents for gene transfer in the nervous system. J Neurosci Methods 71: 125-132, 1997

45. Kassis AI, Taube RA: Efficient radiolabeling of mammalian cells using 111In-tagged liposomes. Int J Rad Appl Instrum B 14:33-35, 1987

46. Kondo S, Ishizaka Y, Okada T, et al: FADD gene therapy for malignant gliomas in vitro and in vivo. Hum Gene Ther 9: 1599-1608, 1998

47. Kondo S, Kondo Y, Li G, et al: Targeted therapy of human malignant glioma in a mouse model by $2-5 \mathrm{~A}$ antisense directed against telomerase RNA. Oncogene 16:3323-3330, 1998

48. Kondo S, Tanaka Y, Kondo Y, et al: Retroviral transfer of CPP32beta gene into malignant gliomas in vitro and in vivo. Cancer Res 58:962-967, 1998

49. Kramm CM, Sena-Esteves M, Barnett FH, et al: Gene therapy for brain tumors. Brain Pathol 5:345-381, 1995

50. Kroll RA, Neuwelt EA: Outwitting the blood-brain barrier for therapeutic purposes: osmotic opening and other means. Neurosurgery 42:1083-1100, 1998

51. Kroll RA, Pagel MA, Muldoon LL, et al: Improving drug delivery to intracerebral tumor and surrounding brain in a rodent model: a comparison of osmotic versus bradykinin modification of the blood-brain and/or blood-tumor barriers. Neurosurgery 43: 879-889, 1998

52. Lachmann RH, Efstathiou S: The use of herpes simplex virusbased vectors for gene delivery to the nervous system. Mol Med Today 3:404-411, 1997

53. LeMay DR Kittaka M, Gordon EM, et al: Intravenous RMP-7 increases delivery of ganciclovir into rat brain tumors and enhances the effects of herpes simplex virus thymidine kinase gene therapy. Hum Gene Ther 9:989-995, 1998

54. Lubinski J, Nagashunmugam T, Friedman HM: Viral interference with antibody and complement. Semin Cell Dev Biol 9: 329-337, 1998

55. Lubinski JM, Wang L, Soulika AM, et al: Herpes simplex virus type 1 glycoprotein $\mathrm{gC}$ mediates immune evasion in vivo. J Virol 72:8257-8263, 1998

56. Martin JB: Gene therapy and pharmacological treatment of inherited neurological disorders. Trends Biotechnol 13:28-35, 1995

57. Matsukado K, Inamura T, Nakano S, et al: Enhanced tumor uptake of carboplatin and survival in glioma-bearing rats by intracarotid infusion of bradykinin analog, RMP-7. Neurosurgery 39:125-134, 1996

58. Millauer B, Longhi MP, Plate KH, et al: Dominant-negative inhibition of Flk-1 suppresses the growth of many tumor types in vivo. Cancer Res 56:1615-1620, 1996

59. Mineta T, Rabkin SD, Martuza RL: Treatment of malignant gliomas using ganciclovir-hypersensitive, ribonucleotide reductase-deficient herpes simplex viral mutant. Cancer Res 54: 3963-3966, 1994

60. Moolten FL: Tumor chemosensitivity conferred by inserted herpes thymidine kinase genes: paradigm for a prospective cancer control strategy. Cancer Res 46:5276-5281, 1986

61. Neuwelt EA (ed): Implications of the Blood-Brain Barrier and its Manipulation. New York: Plenum Press, Vols 1 and 2, 1989

62. Neuwelt EA, Abbott NJ, Drewes L, et al: Cerebrovascular biology and the various neural barriers: challenges and future directions. Neurosurgery 44:604-609, 1999

63. Neuwelt EA, Pagel MA, Dix RD: Delivery of ultraviolet-inactivated 35S-herpesvirus across an osmotically modified bloodbrain barrier. J Neurosurg 74:475-479, 1991

64. Nielsen LL, Maneval DC: P53 tumor suppressor gene therapy for cancer. Cancer Gene Ther 5:52-63, 1998 
65. Nilaver G, Muldoon LL, Kroll RA, et al: Delivery of herpes virus and adenovirus to nude rat intracerebral tumors after osmotic blood-brain barrier disruption. Proc Natl Acad Sci USA 92:9829-9833, 1995

66. Nolta J, Yu X, Bahner I, et al: Retroviral mediated transfer of the human glucocerebrosidase gene into culture Gaucher bone marrow. J Clin Invest 90:342-348, 1992

67. Oyen WJ, Boerman OC, Storm G, et al: Labelled Stealth liposomes in experimental infection: an alternative to leukocyte scintigraphy? Nucl Med Commun 17:742-748, 1996

68. Peltekian E, Parrish E, Bouchard C, et al: Adenovirus-mediated gene transfer to the brain: methodological assessment. J Neurosci Methods 71:77-84, 1997

69. Rabkin SD, Mineta T, Miyatake S, et al: Gene therapy: targeting tumor cells for destruction. Hum Cell 9:265-276, 1996

70. Rainov NG, Dobberstein KU, Sena-Esteves M, et al: New prodrug activation gene therapy for cancer using cytochrome P450 4B1 and 2-aminoanthracene/4-ipomeanol. Hum Gene Ther 9: 1261-1273, 1998

71. Rainov NG, Zimmer C, Chase M, et al: Selective uptake of viral and monocrystalline particles delivered intra-arterially to experimental brain neoplasms. Hum Gene Ther 6:1543-1552, 1995

72. Ram Z, Culver KW, Oshiro EM, et al: Therapy of malignant brain tumors by intratumoral implantation of retroviral vectorproducing cellss. Nat Med 3:1354-1361, 1997

73. Rapoport SI, Fredericks WR, Ohno K, et al: Quantitative aspects of reversible osmotic opening of the blood-brain barrier. Am J Physiol 238:R421-R431, 1980

74. Rapoport SI, Robinson PJ: Tight-junctional modification as the basis of osmotic opening of the blood-brain barrier. Ann NY Acad Sci 481:250-267, 1986

75. Rosenberg SA, Aebersold P, Cornetta K, et al: Gene tranfer into humans-immunotherapy of patients with advanced melanoma, using tumor-infiltrating lymphocytes modified with retroviral gene transduction. N Engl J Med 323:570-578, 1990

76. Roth JA, Swisher SG, Merritt JA, et al: Gene therapy for nonsmall cell lung cancer: a preliminary report of a phase I trial of adenoviral p53 gene replacement. Semin Oncol 25 (3 Suppl 8):33-37, 1998

77. Schellingerhout D, Bogdanov A Jr, Marecos E, et al: Mapping the in vivo distribution of herpes simplex virions. Hum Gene Ther 9:1543-1549, 1998

78. Silbergeld DL, Rostomily RC, Alvord EC Jr: The cause of death in patients with glioblastoma is multifactorial: clinical factors and autopsy findings in 117 cases of supratentorial glioblastoma in adults. J Neurooncol 10:179-185, 1991

79. Smiley ML, Friedman HM: Binding of complement component $\mathrm{C} 3 \mathrm{~b}$ to glycoprotein $\mathrm{C}$ is modulated by sialic acid on herpes simplex virus type 1-infected cells. J Virol 55:857-861, 1985

80. Srinivas RV, Birkedal B, Owens RJ, et al: Antiviral effects of apolipoprotein A-I and its synthetic amphipathic peptide analogs. Virology 176:48-57, 1990

81. Srinivas RV, Venkatachalapathi YV, Rui Z, et al: Inhibition of virus-induced cell fusion by apolipoprotein A-I and its amphipathic peptide analogs. J Cell Biochem 45:224-237, 1991

82. Srivastava S, Katayose D, Tong YA, et al: Recombinant adenovirus vector expressing wild-type p53 is a potent inhibitor of prostate cancer cell proliferation. Urology 46:843-848, 1995

83. Sturtz FG, Waddell K, Shulok J, et al: Variable efficiency of the thymidine kinase/ganciclovir system in human glioblastoma cell lines: implications for gene therapy. Hum Gene Ther 8: 1945-1953, 1997

84. Takamiya Y, Short MP, Moolten F, et al: An experimental model of retrovirus gene therapy for malignant brain tumors. J Neurosurg 79:104-110, 1993

85. Tanaka T, Cao Y, Folkman J, et al: Viral vector-targeted antiangiogenic gene therapy utilizing an angiostatin complementary DNA. Cancer Res 58:3362-3369, 1998

86. Thakur M, Coleman RE, Welch MJ: Indium-111-labeled leukocytes for the localization of abscesses: preparation, analysis, tissue distribution, and comparison with gallium-67 citrate in dogs. J Clin Lab Med 89:217-228, 1977

87. Thormar H, Isaacs CE, Brown HT, et al: Inactivation of enveloped viruses and killing of cells by fatty acids and monoglycerides. Antimicrob Agents Chemother 31:27-31, 1987

88. Tjuvajev J, Kolesnikov Y, Joshi R, et al: Anti-neoplastic properties of human corticotropin releasing factor: involvement of the nitric oxide pathway. In Vivo 12:1-10, 1998

89. Uckert $\mathrm{W}$, Walther $\mathrm{W}$ : Retrovirus-mediated gene transfer in cancer therapy. Pharmacol Ther 63:323-347, 1994

90. Wallner KE, Galicich JH, Krol G, et al: Patterns of failure following treatment for glioblastoma multiforme and anaplastic astrocytoma. Int J Radiat Oncol Biol Phys 16:1405-1409, 1989

91. Weissleder R, Moore A, Mahmood U, et al: In vivo MR imaging of transgene expression. Nat Med 6:351-355, 2000

92. Wivel NA, Wilson JM: Methods of gene delivery. Hematol Oncol Clin North Am 12:483-501, 1998

93. Yoon SS, Nakamura H, Darroll BP, et al: An oncolytic herpes simplex virus type 1 selectively destroys diffuse liver metastases from colon carcinoma. Faseb J 14:301-311, 2000

94. Zinn KR, Douglas JT, Smyth CA, et al: Imaging and tissue biodistribution of 99mTc-labeled adenovirus knob (serotype 5). Gene Ther 5:798-808, 1998

Manuscript received February 15, 2000.

Accepted in final form March 30, 2000.

Address reprint requests to: James P. Basilion, Ph.D., MGH East Building 149, 13th Street, \#5406, Charlestown, MA 02129. email:basilion@helix.mgh.harvard.edu. 